\title{
POLYGENIC INHERITANCE OF AGGRESSIVENESS IN USTILAGO HORDEI
}

\author{
Y. A. EMARA \\ Department of Biology, Memorial University, St John's, Newfoundland, Canada \\ and \\ G. SIDHU \\ Department of Botany, University of British Columbia, Vancouver, Canada
}

Received 31.iii.73

\begin{abstract}
SUMMARY
It has been suggested previously that polygenes play an important role in hostparasite relationships, especially in controlling horizontal resistance of the host and aggressiveness of the parasite. Also, quantitative characters in many fungi were found to be under polygenic control. In the fungus Ustilago hordei, causing the disease covered smut in barley, the ordered tetrads of two teliospores homozygous for the recessive virulence allele $U h v$-1 were selfed and crossed in all compatible combinations and the resulting 16 dikaryons were tested on the barley variety Vantage. Aggressiveness (i.e. degree of infection) was found to be a continuous character genetically controlled by polygenes which modify the expression of the recessive virulence allele $U h v-1$. The analysis of variance showed a large amount of variability in aggressiveness both between and within the teliospores. It also showed that the dikaryons resulting from crossing were significantly more aggressive than those resulting from selfing, suggesting that the alleles for higher levels of aggressiveness are dominant and indicating the existence of heterosis. The results showed the importance of the genetic control of aggressiveness; about 65 per cent of the variability was due to genetic causes while 35 per cent was due to environmental ones. They also showed that the genetic control of the polygenes was not simply additive, there was an amount of gene interaction, which could be due to dominance, epistasis or both.
\end{abstract}

\section{InTRODUCTION}

INHERITANCE of virulence in many plant pathogens has been shown to be controlled by major genes. However, in many situations in which it has not been possible to demonstrate such simple control, it is suggested that polygenic systems are in action (Person and Sidhu, 1971). Also, according to Van der Plank the horizontal resistance of the host and the aggressiveness of the parasite (both non-specific in their interaction) seem often to be polygenically inherited (Van der Plank, 1968). Although there is no doubt that additional knowledge of the role of polygenes would contribute greatly to our understanding of the genetics of host-parasite interactions, the difficulties encountered in studying polygenic systems in this context have been a discouraging factor.

Quantitative characters such as growth rate in Schizophyllum commune (Simchen and Jinks, 1964), Collybia velutipes (Croft and Simchen, 1965; Simchen, 1965) and Aspergillus nidulans (Jinks et al., 1966) as well as spore size in Neurospora crassa (Pateman, 1955) were shown to be controlled by polygenes. In addition, direct evidence from tetrad analyses has demonstrated 
the segregation of polygenes controlling spore size in Neurospora crassa (Pateman and Lee, 1960).

The fungus Ustilago hordei (Pers.) Lagerh., causing the disease covered smut of barley, is a basidiomycete coexisting with its host barley (Hordeum vulgare $\mathrm{L}$.). In this fungus the recessive allele at the recently identified locus Uh $v$-l was shown to determine virulence against the variety Vantage (Sidhu and Person, 1971). However, among cultures all of which were homozygous for this recessive allele, the percentage of infected plants was quite variable, ranging from 17 to 83 per cent on genetically uniform barley plants of that variety. If this variability were genetic it would imply that, in addition to the major virulence gene, there are other genes which are able to modify its expression, i.e. a separate gene system which determines the degree of infection in virulent combinations.

\section{Materials AND methods}

Different strains or genotypes of a pathogen may differ in two aspects regarding their capability of causing infection on a particular host variety. First, whether or not the strains are capable of causing infection; thus, the

TABLE 1

Mean of aggressiveness of the 16 dikaryon combinations

\begin{tabular}{lrrrrrc} 
& $\mathrm{E}_{2}^{+}$ & \multicolumn{1}{c}{$\mathrm{E}_{4}^{+}$} & \multicolumn{1}{c}{$\mathrm{F}_{2}^{+}$} & $\mathrm{F}_{3}^{+}$ & Total & Average \\
$\mathrm{E}_{1}^{-}$ & $38 \cdot 3$ & $20 \cdot 1$ & $49 \cdot 5$ & $51 \cdot 7$ & $159 \cdot 6$ & $39 \cdot 9$ \\
$\mathrm{E}_{3}^{-}$ & $37 \cdot 9$ & $32 \cdot 5$ & $68 \cdot 9$ & $68 \cdot 6$ & $207 \cdot 9$ & $52 \cdot 0$ \\
$\mathrm{~F}_{1}^{-}$ & $43 \cdot 1$ & $28 \cdot 9$ & $40 \cdot 6$ & $41 \cdot 0$ & $153 \cdot 6$ & $38 \cdot 4$ \\
$\mathrm{~F}_{4}^{-}$ & $64 \cdot 7$ & $47 \cdot 9$ & $56 \cdot 6$ & $57 \cdot 3$ & $226 \cdot 5$ & $56 \cdot 6$ \\
Total & $184 \cdot 0$ & $129 \cdot 4$ & $215 \cdot 6$ & $218 \cdot 6$ & & \\
Average & 46.0 & $32 \cdot 4$ & $53 \cdot 9$ & $54 \cdot 7$ & &
\end{tabular}

strains which are capable of causing infection are called virulent, while those not capable of causing infection are called avirulent with regard to a particular host variety. Second, the degree of infection; the virulent strains may differ in their degree of infection, and this is referred to as a difference in aggressiveness. It should be noted that the above definitions of virulence and aggressiveness are slightly different and more general than those proposed by Van der Plank (1968).

Teliospores from the smut sori which develop in the spikelets germinate on artificial medium and immediately go through meiosis. The four products of a single teliospore form an ordered tetrad from which four haploid gametic monosporidial cultures can be established by micromanipulation. Two of the monosporidia are + and two are -, and they are numbered from top to bottom. Because the mating system is dipolar it is possible to establish four infective diploid lines when the gametes of one spore are brought together in all compatible combinations. Mating within and between teliospores can be made by mixing compatible monosporidial cultures to form the infective dikaryon which is an obligate parasite on barley. Infection is done by soaking the seeds in the inoculum for about 20 minutes under vacuum, then pouring off the excess inoculum and letting the seeds dry for 3 days at room temperature.

The two teliospores designated $\mathbf{E}$ and $\mathrm{F}$ used in this study are from material collected at the Canadian prairies, and they are homozygous for 
the virulence recessive allele $U h v$-1 (Sidhu and Person, 1971). The ordered tetrads of these teliospores were selfed and crossed in all possible combinations to produce 16 dikaryons (table 1). Each culture of these dikaryons was used to inoculate about 150 seeds of the barley variety Vantage (CI-7324). The inoculated seeds, along with a control treated with medium only, were sown in the greenhouse and after three weeks were transferred to the field in early May. Six randomised complete blocks were used, with each dikaryon and the control represented by two rows randomly distributed per block. Each row was 5 feet long and contained eight plants. Aggressiveness was recorded in terms of percentage of infected spikes per row. The data were transformed to arcsine to allow analysis of variance to be performed.

\section{Results}

Infection in all control rows was zero proving that the field and uninoculated seeds were free of $U$. hordei. Thus the control results were excluded from the statistical analysis. From table 1 it is evident that all dikaryons are virulent as they cause infection, this was expected as they are all homozygous

TABle 2

Analysis of variance of aggressiveness; all dikaryons

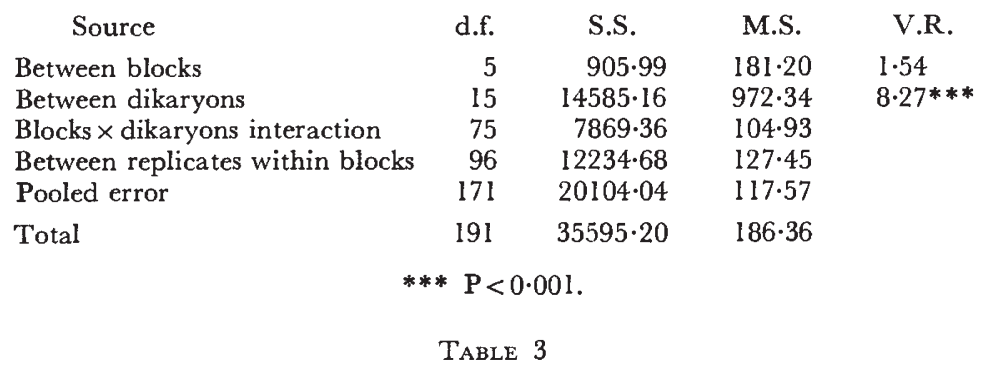

Analysis of variance of aggressiveness; grouped dikaryons

Source

Between selfs and crosses

Between teliospores

Between dikaryons within teliospores

Between reciprocal sets of crosses

Between dikaryons within reciprocal crosses

Pooled error d.f.

$$
\text { S.S. }
$$

M.S.

$2956 \cdot 31$

$2897 \cdot 95$

$406 \cdot 87$

$1712 \cdot 90$

$761 \cdot 30$

$117 \cdot 57$
V.R.

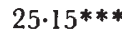

$24 \cdot 65 * * *$

$3 \cdot 46 * *$

$14 \cdot 57 * * *$

$6 \cdot 48 * * *$

$$
* * 0.01>\mathrm{P}>0.001 . * * * \mathrm{P}<0.001 \text {. }
$$

recessive for the virulence allele $U h v-1$. However, the degree of infection (i.e. aggressiveness) is quite variable among these dikaryons, ranging from 68.9 per cent down to $20 \cdot 1$ per cent infection. Monosporidia of teliospore $F$ seem to show more aggressiveness than those of teliospore $E$, as most of the $\mathrm{F}$ monosporidia combinations fall in the upper half of the range. It is also clear that most of the dikaryons resulting from crossing are more aggressive than those resulting from selfing. In table 2 variance between dikaryons is highly significant, indicating a lot of genetic variability for aggressiveness among dikaryons. Further analysis in table 3 throws light on the distribution of this variability. First, the largest amount of difference is between dikaryons from selfing and those from crossing. Second, there is considerable difference 
between the two teliospores. Third, the smallest amount of variance is, as expected, within teliospores, although it is still highly significant. Fourth, the two previous types of variability are reflected in the item between reciprocal sets of crosses. Fifth, the item between dikaryons within reciprocal crosses is more significant than that between dikaryons within teliospores indicating that variability between dikaryons resulting from crosses is larger than variability between dikaryons resulting from selfing. It is obvious from table 4 that the + monosporidia contribute more variability than the - monosporidia and that interaction between them is highly significant.

TABLE 4

Analysis of variance of aggressiveness; breakdown of variance among dikaryons and expectation of mean squares

$\begin{array}{crrrrr}\text { Source } & \text { d.f. } & \text { S.S. } & \text { M.S. } & \text { V.R. } & \text { Expectation of M.S. } \\ + \text { monosporidia } & 3 & 6421.43 & 2140.48 & 20 \cdot 40 * * * & \sigma_{E}^{2}+24 \sigma_{P+}^{2} \\ \text { - monosporidia } & 3 & 3750.96 & 1250 \cdot 32 & 11.92 * * * & \sigma_{E}^{2}+24 \sigma_{P-}^{2} \\ +\times \text { - interaction } & 9 & 4412 \cdot 77 & 490 \cdot 31 & 4.67 * * * & \sigma_{E}^{2}+6 \sigma_{I}^{2} \\ \text { Blocks } \times \text { dikaryons } & 75 & 7869.36 & 104.93 & & \sigma_{E}^{2} \\ * * * & \text { P }<0.001 . \\ \sigma_{E}^{2} & =\text { Environmental component of variation. } \\ \sigma_{P+}^{2} & =\text { Additive genetical component contributed by + monosporidia. } \\ \sigma_{P-}^{2} & =\text { Additive genetical component contributed by - monosporidia. } \\ \sigma_{I}^{2} & =\text { Non-additive genetical component. }\end{array}$

TABLE 5

Estimates of components of variation of aggressiveness

$\begin{array}{rcccc}V_{P} & V_{A} & V_{I} & V_{G} & V_{E} \\ 301 \cdot 69 & 132 \cdot 53 & 64 \cdot 23 & 196 \cdot 76 & 104 \cdot 93 \\ (100 \%) & (43.9 \%) & (21 \cdot 3 \%) & (65 \cdot 2 \%) & (34 \cdot 8 \%)\end{array}$

The expectation of mean squares is also shown in table 4 and from it the estimates of components of variation were computed and shown in table 5 . From this table we can see that about 35 per cent of the variability in aggressiveness is due to environmental causes $\left(V_{E}\right)$ while the genetic causes $\left(V_{G}\right)$ account for about 65 per cent in which the additive genetic effect $\left(V_{A}\right)$ contributes 43.9 per cent of the total variability $\left(V_{P}\right)$ and non-additive effect $\left(V_{I}\right)$ contributes $21 \cdot 3$ per cent.

\section{Discussion}

Although all the dikaryons were homozygous for the virulence allele, they showed genetic variability in their aggressiveness (i.e. degree of infection) as the item between dikaryons was highly significant (table 2). Thus, it is suggested that those genes controlling aggressiveness act as modifiers to the expression of the recessive major allele $U h v-1$. From table 1 it is obvious that aggressiveness is a continuous character indicating that its heritable variation is under polygenic control. All the results clearly indicate that this character is highly variable as variability is even evident within the products of single teliospores. As might be expected, variability between teliospores is much higher than within teliospores. 
The fact that dikaryons resulting from crosses are generally more aggressive than those resulting from selfing is a good indication that the alleles for higher levels of aggressiveness are dominant and that heterosis is evident.

Although reciprocal differences do represent reciprocals between the diploids $\mathrm{E}$ and $\mathrm{F}$, they do not represent reciprocals between the haploid products as for example $\mathrm{E}_{2} \times \mathrm{E}_{1}$ can be made only one way. Therefore, the existence of a significant reciprocal item (which groups $\mathrm{E}_{2} \times \mathrm{F}_{1}, \mathrm{E}_{2} \times \mathrm{F}_{4}$, $\mathrm{E}_{4} \times \mathrm{F}_{1}, \mathrm{E}_{4} \times \mathrm{F}_{4}$ v. $\left.\mathrm{F}_{2} \times \mathrm{E}_{1}, \mathrm{~F}_{2} \times \mathrm{E}_{3}, \mathrm{~F}_{3} \times \mathrm{E}_{1}, \mathrm{~F}_{3} \times \mathrm{E}_{3}\right)$ may merely reflect segregation within $\mathrm{E}$ and $\mathrm{F}$ because the samples of haploids are so small. In fact if we test the between reciprocals M.S. against the between dikaryons within reciprocals M.S. we find it is not significant.

It is evident from the estimates of components of variation that the genetic control is more important than the environmental one. However, an appreciable part of the genetic control is due to interaction between the two parental genotypes. The source of this interaction can be allelic interaction, i.e. dominance, non-allelic interaction or both.

It will be of considerable interest to select for these genes to develop strains of high and low aggressiveness, from which further information concerning the nature of these genes could be gained, through crossing and back crossing; this work is currently in progress. Information of this kind, concerning the pathogen, will contribute to a better understanding of horizontal resistance in the host. Although it will probably be necessary to develop horizontal resistance in many plants of economic value, in order to prevent the sudden collapse of resistance conferred by major genes (Van der Plank, 1968), almost nothing has been done to produce the needed fundamental genetic information.

The present rather simple system in the pathogen (i.e. one major gene controlling virulence and a series of polygenes modifying it) may be matched by a similar system for resistance in the host, a possibility which may extend the gene-for-gene concept to polygenes (Person et al., 1962). Sidhu and Person have already identified a gene in the host for resistance matching this major gene for virulence (Sidhu and Person, 1972).

Finally, it should be made clear that since the sample of monosporidia in this study originated from two teliospores, it is too limited to be random. Consequently, the above results and conclusions are limited to the two tetrads of teliospores $\mathbf{E}$ and $\mathbf{F}$. Nevertheless, other studies in progress by the senior author, indicate that the results and conclusions of the present study could be applicable to $U$. hordei as a whole.

Acknowledgments.-We wish to thank Dr C. Person for providing the cultures and many facilities, and for his advice and criticism throughout this investigation. Financial support from the National Research Council of Canada is gratefully acknowledged.

\section{REFERENCES}

CROFT, J. H., AND sIMGHEN, G. 1965. Natural variation among monokaryons of Collybia velutipes. Amer. Naturalist, 99, 451-462.

JINKS, J. L., CATEN, C. E., SIMGHEN, G., AND GROFT, J. H. 1966. Heterokaryon incompatibility and variation in wild populations of Aspergillus nidulans. Heredity, 21, 227-239.

pateman, J. A. 1955. Polygenic inheritance in Neurospora. Nature, 176, 1274-1275. 
Pateman, J. A., AND LEE, T. o. 1960. Segregation of polygenes in ordered tetrads. Heredity, $15,351-361$.

PERson, C., AND SIDHU, G. 1971. Genetics of host-parasite interrelationships. Mutation Breeding for Disease Resistance, International Atomic Energy Agency, Vienna, 31-38.

PERSON, C., SAMBORSKI, D. J., AND ROHRINGER, R. 1962. The gene-for-gene concept. Nature, 194, 561-562.

SIDHU, G., AND PERSON, C. 1971. Genetic control of virulence in Ustilago hordei. II. Segregations for higher levels of virulence. Can. F. Genet. Cytol., 13, 173-178.

SIDHU, G., AND PERSON, c. 1972. Genetic control of virulence in Ustilago hordei. III. Identification of genes for host resistance and demonstration of gene-for-gene relations. Can. $\mathcal{F}$. Genet. Cytol., 14, 209-213.

simchen, G. 1965. Variation in dikaryotic populations of Collybia velutipes. Genetics, 51, 769-721.

SIMCHEN, G., AND JINKs, J. L. 1964. The determination of dikaryotic growth rate in the basidiomycete Schizophyllum commune: A biometrical analysis. Heredity, 19, 629-649.

van der Plank, J. E. 1968. Disease Resistance in Plants. New York: Academic Press. 